\title{
An Exploratory Examination of Social Media Use and Risky Sexual Practices: A Profile of Women in Rural Appalachia Who Use Drugs
}

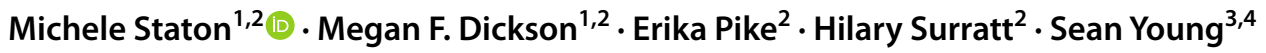

Accepted: 21 January 2022 / Published online: 1 February 2022

(c) The Author(s), under exclusive licence to Springer Science+Business Media, LLC, part of Springer Nature 2022

\begin{abstract}
$\mathrm{HIV} / \mathrm{HCV}$ risk behavior among women who use drugs is often exacerbated within high risk networks. The use of social media platforms such as Facebook to identify sex partners within these high-risk networks has not been examined among rural Appalachian women who use drugs. This paper provides an exploratory examination of Facebook use to identify sex partners among rural Appalachian women who use drugs, as well as associated risky sexual practices. Rural Appalachian women were randomly selected from two rural jails, consented, screened for eligibility (including drug use), and interviewed prior to jail release. Findings indicated that using Facebook to meet sex partners was associated with exchanging sex for drugs or money and having a male casual partner during the same time frame. These study findings suggest that the use of social media for high-risk sexual practices may provide a valuable platform for intervention delivery, particularly in resourcedeprived areas where formal prevention and treatment services are limited.
\end{abstract}

Keywords Women offenders $\cdot$ Injection drug use $\cdot$ Risky sex $\cdot$ Social media

\section{Introduction}

Women with substance use disorder (SUD) are at increased risk for human immunodeficiency virus (HIV) and hepatitis $\mathrm{C}$ virus (HCV) relative to women in the general population due to a higher likelihood of engaging in risky drug use (e.g., shared injection practices) and risky sexual practices (e.g., unprotected sex, having multiple sex partners, and having partners who also inject drugs) [1-3]. Women who use drugs are at increased risk for HIV/HCV compared to men because they are more likely to report initiation of injection use due to social pressure, initiating injection with

Michele Staton

mstaton@uky.edu

1 Center on Drug and Alcohol Research, University of Kentucky, Lexington, KY, USA

2 Department of Behavioral Science, University of Kentucky College of Medicine, 1100 Veterans Dr., Lexington, KY 40536, USA

3 Department of Emergency Medicine, School of Medicine, University of California, Irvine, Irvine, USA

4 Department of Informatics, School of Information and Computer Sciences, University of California, Irvine, Irvine, USA their partner, and being injected by their partner [4]. Recent national data indicate rising rates of HIV infection among women attributable to injection drug use, reaching $40 \%$ in 2019 [1]. Injection drug use has also been associated with risky sexual practices among women including sex with someone who injects drugs, trading sex for drugs or money, having sex before or after injection, and being diagnosed with an STI [5, 6]. These trends are also apparent at the state level where Kentucky is among the top ten states in the nation identified as having a "heavy rural HIV burden" with increasing rates of new HIV diagnoses attributed to injection drug use [7]. Thus, it is critical to understand unique risks associated with HIV and HCV among rural women.

While HIV/HCV risk behaviors are common among women who use drugs in general, they are more pronounced among justice-involved women. One study suggested that $69 \%$ of women in prison and $72 \%$ of women in jail meet criteria for a SUD [8], rates considerably higher than incarcerated men. Studies focused on HIV/HCV risk among justiceinvolved women with SUD have reported similar findings associated with high risk drug use and risky sexual practices including unprotected sex with multiple partners, anal sex, partners who injected drugs, sex with injecting partners, and sex exchange for drugs or money [9-12]. Women reentering the community from incarceration have also been 
shown to be at increased risk of engaging in illicit drug use and transactional sex compared to women with no justice involvement [13].

High-risk behavior among justice-involved women has also been highlighted in rural Appalachia, an area of the country severely impacted by the opioid epidemic. A recent study of rural Appalachian women in jails found that $75 \%$ reported lifetime injection of drugs, $60 \%$ reported injecting drugs and sharing needles in the 6 months before jail, $60 \%$ of the sample tested HCV positive, and less than half reported ever being in treatment for SUD [14]. Some studies have suggested that risk behavior may be associated with limited availability of sexual partners $[15,16]$, which is likely the case in rural Appalachia where social networks are closely intertwined. One study found that relationships with sexual partners moderated the relationship between drug use severity and incarceration history among rural Appalachian women who used drugs [3]. Similarly, involvement with male sexual partners who injected drugs increased the likelihood that rural women also initiated injection drug use [17]. Additionally, women reported trading sex for money and/or drugs with partners in their network multiple times [14]. These studies suggest there may be unique risks for HIV/HCV among women in rural Appalachia.

Rural Appalachians, including those who use substances, are also using social media. Social media use, particularly Facebook (FB), is common with $69 \%$ of American adults and $67 \%$ in rural areas reporting regular FB use [18]. Most women (77\%) in the Pew Research [18] study reported using $\mathrm{FB}$, and the majority of FB users (70\%) reported visiting the site at least daily. In an analysis of social media use, rural individuals appeared to use social media as a way to foster relationships and to communicate with those whom they already have a connection [19]. Social media use has also been well documented among individuals who use substances [20, 21]. Among rural Appalachian women, almost two-thirds of a randomly selected sample of women who use drugs reported having a FB account that they checked regularly, and study retention and follow-up were significantly higher among FB users [22]. Thus, it is important to examine whether social media platforms may play a role in facilitating HIV/HCV risk behavior within rural Appalachian social networks.

Considering the widespread use of FB among individuals in rural Appalachia, research is needed on the extent to which FB may facilitate drug use and sex risk networks among women who use substances. Research has shown that FB and other social media platforms are often used to identify sex partners; however, the majority of studies in this area have focused on men who have sex with men and predominantly in large urban areas (MSM; [23-25]). MSM who found sexual partners online engaged in riskier sexual behaviors than those who did not [23, 25]. Almost half of
MSM engaging in transactional sex identified their first client through social media or an app that is not designed specifically for sex work [24]. Further, the majority of MSM who had engaged in transactional sex in the last 3 months met a client through social media or a non-sex-work app [24]. One review that focused on online solicitation of heterosexual romantic or sexual partners found evidence that inconsistent condom use may be more common among individuals who seek partners online [26], but research with heterosexuals and women is limited. Because social media has become so widely used among women who use drugs [20, 21], a better understanding of how FB is used to facilitate risk behavior among high-risk women who use substances is warranted.

There is a significant gap in research focusing on the high-risk practice of identifying sex partners through social media among women in general, and women in socially isolated areas like rural Appalachia in particular. This paper has two primary objectives: (1) Profile substance use, sexual risk behaviors, and social media use in this sample of rural, Appalachian, justice-involved women; and (2) Explore risky drug use and sexual behaviors among women who selfreport using social media to connect with sexual partners.

\section{Methods}

\section{Participants}

Adult women (aged 18 and older) were randomly selected from two rural jails in Appalachia and screened for study eligibility as part of a larger study focused on HIV prevention [27]. Participants in the sampling frame were identified as female based on the jail daily census. Study eligibility included: (1) moderate substance use risk based on the NIDA-modified Alcohol, Smoking and Substance Involvement Screening Test (NM-ASSIST) score of 4+ for any drug [28]; (2) self-reported HIV risk behavior in the past 3-months; (3) regular user of Facebook; (4) self-reported HIV negative status; (5) residing in a designated Appalachian county before incarceration; and (6) willingness to participate.

\section{Measures}

\section{Demographics}

All study participants were women, and they were asked to self-report basic demographics including age, race, marital status, parenting status (percentage having children), education (highest grade of education completed), employment, and percentage reporting "money problems" during the 3 months before incarceration. In addition, women were 
asked if they had ever had a driver's license and about the number of days of their current incarceration.

\section{Substance Use}

Screening scores from the NM-ASSIST were included in study analysis. The NM-ASSIST [28, 29] has been used in other trials with justice-involved women because scores can be used to interpret participant risk levels that map to indicators for SUD intervention [3]. The NM-ASSIST specifically screens injection drug use as high-risk, and generates a substance involvement (SI) score for eight different types of drugs.

Other substance use measures were derived from the GAIN [30] and included self-reported "ever" use of the following substances, as well as recent use during the "three months prior to incarceration": alcohol, marijuana, cocaine (powder and crack), prescription opioids (pain medications), street opioids (heroin), anti-anxiety meds, methamphetamine, amphetamines, sedatives, and the use of multiple substances in the same day. Participants were also asked to report whether they had injected drugs during their lifetime or in the 3 months prior to incarceration - specifically reporting whether they had injected prescription pain relievers, prescription stimulants, prescription benzodiazepines, methamphetamine, cocaine, heroin, or speedball.

\section{Sexual Behaviors}

Sexual risk behaviors were derived from the Risk Behavior Assessment, modified for women [31]. Measures of sexual risk behavior included age of first sex, number of lifetime sexual partners, number of sex partners in the 3 months prior to incarceration, number of male casual partners in the 3 months prior to incarceration, percentage reporting sex exchange for drugs or money in their lifetime and the 3 months prior to incarceration, and percentage engaging in unprotected sexual encounters in their lifetime and the 3 months prior to incarceration.

\section{Social Media Use}

Being a self-identified "regular" user of Facebook was a study eligibility criteria. Measures in the current analysis included other social media sites where women have accounts (e.g., Snapchat, Instagram), general reasons for using Facebook and other social media sites (e.g., for news, engaging with friends/family, or finding a hook-up or sexual partner), and amount of time invested in social media sites during an average week. Participants were also asked to report if they had used social media to meet a new sexual partner in the 3 months prior to incarceration and how many sexual partners they had met online during this time.

\section{Procedure}

This study used random sampling to recruit study women participants from two rural jails in central Appalachia. Random sampling began with the daily jail census report, which varies considerably by day (week days versus weekend days). In order to ensure representativeness of the sample, recruitment dates were randomized monthly at each of the two rural jails including alternating the order in which jails were visited each month. On each recruitment day, research staff worked with jail administrators to access the daily census sheet for the names of potential study participants living at the facility. Potential participants were included in the targeted recruitment sampling frame if they self-reported a release date in the upcoming 3 months (verified by jail records).

All women who met initial projected release date screening criterion had an equal opportunity of being selected for study screening. From this sampling frame, research staff then randomly selected (using Research Randomizer, www.randomizer.org) approximately 10 women for study screening during each session. Randomly selected women were invited to participate in a screening session. Screening sessions were conducted in a group format in a private, confidential setting in the jail prior to implementation of COVID-19 visitation restrictions. While participants were in the group room at the same time, they were spaced throughout the room and responded confidentially to screener forms using paper and pencil. While jail staff assisted in escorting women to the screening room, no jail staff or representatives from the criminal justice system were present during the screening sessions. Following implementation of COVID19 restrictions in March 2020, the sampling frame included women who expressed interest in the study by signing up on a sheet placed in each cell. In order to maintain the integrity of random selection, individuals who were expressed interest were entered into a spreadsheet and Research Randomizer was still used to randomly select individuals to screen.

The screening session included informed consent and a question/answer time with the research staff regarding study details. Interested participants were then asked to complete screening assessments including the NM-ASSIST, anticipated release date from jail, their "home" county to ensure they were from an Appalachian area, Facebook use prior to incarceration, self-reported HIV status, and confirmation of interest to participate in the study. Screening assessments were reviewed, and women who met all study eligibility were asked to schedule a study baseline interview within the week.

During the study recruitment phase between May 29, 2019 and March 31, 2021, 242 women were randomly selected from the two target jails. Of those, 189 (78\%) participated in the study screening sessions in the jails (23 
refused to participate, 7 were released early, 17 were not available on their screening day, and 6 did not screen for other reasons). Among women who participated in screening, 67 (35\%) screened eligible for the study. The remaining 122 participants did not meet study eligibility criteria due to the following reasons (categories not mutually exclusive): not being released during 3 month time frame $(n=91)$, not engaging in any risky sexual practices $(n=14)$, not being from an Appalachian county $(n=23)$, not being a regular Facebook user $(n=10)$, and two $(n=2)$ refusals. Only 6 women did not meet the NM-ASSIST criteria, suggesting that $97 \%$ of women randomly selected from the jail for screening reported substance use consistent with a moderate need for intervention (score of $4+$ on the ASSIST).

Of the 67 participants who screened eligible, baseline interviews were completed with 60 . Similar to other studies with rural incarcerated women in jails (3), anticipating jail release dates proved to be challenging due to unpredictable court dates, limited information through court records, and arrangements for bail. Thus, despite screening for anticipated release date (both through jail records and self-report), a few women $(n=5)$ were released early between screening eligible and completing the baseline. In addition, one woman was transferred to prison and one woman refused to proceed with the study. The final study sample $(\mathrm{N}=60)$ participated in face-to-face interviews in a private room in each jail using Computer-Assisted Personal Interview (CAPI) software and using Zoom ${ }^{\circledR}$ videoconferencing following implementation of COVID-19 visitation restrictions (March 2020). Research staff were female interviewers from the local Appalachian area, and they were trained on jail facility policies and procedures by jail administrators prior to study implementation. Participants were paid \$25 for the baseline interview, and all study screening and data collection procedures were approved by the university IRB and protected under a federal Certificate of Confidentiality.

\section{Analytic Plan}

The overall study objectives include: (1) Profiling substance use, sexual risk behaviors, and social media use in this sample of rural Appalachian women; and (2) Exploring risky drug use and sexual behaviors among women who self-report using social media to connect with sexual partners. To meet the first study objective, descriptive statistics were first used to profile sample demographic characteristics, in addition to describing women's social media use, substance use patterns, and risky sexual behaviors. After profiling the sample, the second study objective was met by comparing participants who self-reported using social media to meet sexual partners $(n=21)$ in the 3 months prior to incarceration to those who did not connect with sexual partners via social media $(n=39)$. Specifically, a series of chi-square tests and $t$-tests were used to identify differences across groups in drug use patterns and risky sexual behaviors. In addition, the unadjusted prevalence ratios and 95\% confidence intervals were calculated to further quantify the association between finding a sex partner via social media and other risk behaviors $[32,33]$. Analyses were conducted using IBM SPSS version 28.0.

\section{Results}

\section{Profile of Substance Use, Sexual Risk Behaviors, and Social Media Use}

As presented in Table 1, all study participants $(\mathrm{N}=60)$ selfreported being white with an average age of $36.4(\mathrm{SD}=8.1)$ and an average of 12.1 years of education $(\mathrm{SD}=2.0)$. The majority reported having children $(91.7 \%)$ and $81.7 \%$ were currently unmarried (including being divorced, separated, never married, and widowed). Most participants (93.3\%) were unemployed or not working in the 3 months prior to incarceration, with $68.3 \%$ reporting experiencing money problems during that time period.

As previously mentioned, study eligibility criteria included substance use (measured by a score of $4+$ on the NM-ASSIST). Of the participants who entered the study, the highest average NM-ASSIST SI score across all substances was 36.7 ( $\mathrm{SD}=4.9)$. The highest average SI scores for specific substance were $34.5(\mathrm{SD}=9.2)$ for methamphetamine, followed by $25.4(\mathrm{SD}=13.6)$ for prescription opioids. All 60 women (100.0\%) reported using alcohol and marijuana in their lifetime, as well as high rates of illicit prescription opioid use (98.3\%), methamphetamine (95.0\%), and antianxiety medications (93.3\%). In the 3 months prior to incarceration (see Table 1), fewer than two-thirds of participants (58.3\%) reported using alcohol, but drug use continued to be highly prevalent. Specifically, $90.0 \%$ reported having used methamphetamine for an average of 67.2 days $(\mathrm{SD}=34.8)$, followed by prescription opioids (88.3\%) for an average of 49.9 days ( $\mathrm{SD}=41.4)$, and marijuana $(71.7 \%)$ for an average of 37.9 days $(\mathrm{SD}=39.5)$. Most participants also reported using multiple drugs in the same day (98.3\% lifetime; $90.0 \%$ 3 months prior to incarceration).

With regard to sexual risk behavior, women reported an average of $49.4(\mathrm{SD}=78.5)$ sexual partners in their lifetime and $4.5(\mathrm{SD}=10.6)$ in the 3 months prior to incarceration. Furthermore, $60.0 \%$ reported having a male casual sex partner in the 3 months prior to incarceration. Women reported having sex for the first time at an average of 15.0 years old $(\mathrm{SD}=1.9)$, and most women had had unprotected sex in their lifetime (95.0\%), including the 3 months prior to incarceration $(86.7 \%)$. In addition, more than half $(51.7 \%)$ said they had exchanged sex for money, drugs, or other goods and 
Table 1 Sample profile $(\mathrm{N}=60)$

\begin{tabular}{|c|c|c|c|}
\hline & Percent (n) & Mean (SD) & Range \\
\hline \multicolumn{4}{|l|}{ Demographics } \\
\hline Age & - & $36.4(8.1)$ & $19-52$ \\
\hline Race (\% white) & $100.0 \%(60)$ & - & - \\
\hline Average number of days spent incarcerated & - & $127.1(164.4)$ & $3-739$ \\
\hline Ever had a driver's license (\% yes) & $81.7 \%(49)$ & - & - \\
\hline Marital status (\% unmarried due to divorce, separation, never married, widowed) & $81.7 \%(49)$ & - & - \\
\hline Parenting status (\% reporting having any children) & $91.7 \%(55)$ & - & - \\
\hline Average highest grade of education completed & - & $12.1(2.0)$ & $8-16$ \\
\hline Employment (\% unemployed/not working in 3 months before jail) & $93.3 \%(56)$ & - & - \\
\hline Had money problems in 3 months before jail (\% Yes) & $68.3 \%(41)$ & - & - \\
\hline \multicolumn{4}{|l|}{ Substance use } \\
\hline \multicolumn{4}{|l|}{ Percentage reporting use in 3 Months prior to Incarceration... } \\
\hline Multiple drugs in 1 day & $90.0 \%(54)$ & - & - \\
\hline Methamphetamine & $90.0 \%(54)$ & - & - \\
\hline Prescription opioids & $88.3 \%(53)$ & - & - \\
\hline Marijuana & $71.7 \%(43)$ & - & - \\
\hline Alcohol & $58.3 \%(35)$ & - & - \\
\hline Anti-anxiety meds & $51.7 \%(31)$ & - & - \\
\hline Heroin & $48.3 \%(29)$ & - & - \\
\hline Powder cocaine & $28.3 \%(17)$ & - & - \\
\hline Crack & $20.0 \%(12)$ & - & - \\
\hline Downers, sleeping pills, sedatives & $15.0 \%(9)$ & - & - \\
\hline Amphetamines & $8.3 \%(5)$ & - & - \\
\hline \multicolumn{4}{|l|}{ Sexual risk behavior } \\
\hline Age first time had sex & - & $15.0(1.9)$ & $11-22$ \\
\hline Average number of lifetime sexual partners & - & $49.4(78.5)$ & $4-340$ \\
\hline Average number of sex partners in the 3 months before incarceration ${ }^{a}$ & - & $4.5(10.6)$ & $0-80$ \\
\hline Had a male casual sex partner in the 3 months before incarceration ( $\%$ yes) & $60.0 \%(34)$ & - & - \\
\hline Reported ever exchanging sex for money or drugs & $51.7 \%(31)$ & - & - \\
\hline Had sex in exchange for money or drugs in the 3 months before incarceration & $38.3 \%(23)$ & - & - \\
\hline Reported having unprotected sex in lifetime & $95.0 \%(57)$ & - & - \\
\hline Reported having unprotected sex in the 3 months before incarceration & $86.7 \%(52)$ & - & - \\
\hline Reporting having unprotected sex with casual partner & $88.3 \%(53)$ & - & - \\
\hline \multicolumn{4}{|l|}{ Social media use } \\
\hline \multicolumn{4}{|l|}{ Reported being a member of social media sites } \\
\hline Facebook $^{\mathrm{a}}$ & $100.0 \%(60)$ & & \\
\hline Snapchat & $38.3 \%(23)$ & & \\
\hline Instagram & $30.0 \%(18)$ & & \\
\hline Twitter & $10.0 \%(6)$ & & \\
\hline Other & $16.7 \%(10)$ & & \\
\hline \multicolumn{4}{|l|}{ Reported reasons for using social media } \\
\hline Entertainment & $100.0 \%(60)$ & - & - \\
\hline Messaging/email & $100.0 \%(60)$ & - & - \\
\hline News & $70.0 \%(42)$ & - & - \\
\hline Meeting new people & $63.3 \%(38)$ & - & - \\
\hline Research/general knowledge & $51.7 \%(31)$ & - & - \\
\hline Finding sexual partners & $40.0 \%(24)$ & - & - \\
\hline School/work & $11.7 \%(7)$ & - & - \\
\hline Used social media to meet new sexual partner(s) during 3 months before incarceration & $35.0 \%(21)$ & - & - \\
\hline Number of sexual partners met online during the 3 months before incarceration & $2.2(5.2)$ & - & $0-30$ \\
\hline
\end{tabular}


Table 1 (continued)

\begin{tabular}{|c|c|c|c|}
\hline & Percent (n) & Mean (SD) & Range \\
\hline \multicolumn{4}{|c|}{ Reported time on social media (per week) during 3 months before incarceration } \\
\hline $8+h$ & $94.9 \%(57)$ & - & - \\
\hline $6-8 \mathrm{~h}$ & $1.7 \%(1)$ & - & - \\
\hline $4-6 \mathrm{~h}$ & $1.7 \%(1)$ & - & - \\
\hline $2-4 \mathrm{~h}$ & $1.7 \%(1)$ & - & - \\
\hline
\end{tabular}

${ }^{\mathrm{a}}$ Having a Facebook account was required for study participation

services in their lifetime, though this number was slightly less $(38.3 \%)$ in the 3 months before incarceration. Of those who had exchanged sex in their lifetime $(n=31), 96.8 \%$ reporting having unprotected sex at least some of the time when exchanging sex for money, drugs, or other goods and services.

Participant's social media use is also shown in Table 1. Consistent with study eligibility criteria, all women reported having a Facebook account, followed by Snapchat (38.3\%) and Instagram (30.0\%). Most (94.9\%) reported spending at least $8 \mathrm{~h}$ per week on social media prior to incarceration.

The most frequently cited reasons for typically using social media were (1) messaging and emailing (100.0\%), (2) news $(70.0 \%)$, and 3$)$ meeting new people (63.3\%). Twentyfour participants (40.0\%) reported using social media to find sexual partners, with 21 of those (35.0\%) specifically reporting having used social media to meet a new sexual partner in the 3 months prior to incarceration.

\section{Drug Use, Sexual Behavior, and Social Media Connections}

Table 2 examines group differences in drug use and sexual risk behaviors between women who self-reported finding a sexual partner using social media $(n=21,35 \%)$ in the 3 months prior to incarceration compared to those who had not connected with sexual partners via social media $(n=39,65 \%)$. Although the two groups were similar overall, chi-square and t-tests highlighted some significant differences. Analyses found that those who used social media to find a sexual partner had significantly higher NMASSIST scores for sedatives $(t(58)=-2.54, p=0.014)$ and prescription stimulants $(t(29.0)=-2.25, p=0.032)$. In addition, they were significantly more likely to report having used alcohol $\left(x^{2}(1, \mathrm{~N}=60)=6.80, p=0.009\right)$, marijuana $\left(x^{2}(1, \mathrm{~N}=60)=5.63, p=0.018\right)$, powder cocaine $\left(x^{2}(1, \mathrm{~N}=60)=9.20, p=0.002\right)$, and amphetamines $\left(x^{2}(1, \mathrm{~N}=60)=4.86, p=0.028\right)$ in the 3 months prior to incarceration.

Overall, rates of injection drug use were similar across the two groups. The one exception of injection of speedball where participants in the social media sex partner group were more likely to have injected speedball in their lifetime $\left(x^{2}(1, \mathrm{~N}=60)=4.60, p=0.032\right.$, not reported in Table 2$)$ and in the 3 months prior to incarceration $\left(x^{2}(1\right.$, $\mathrm{N}=60)=4.62, p=0.032$ ). While similar across groups, it should be noted that prevalence of lifetime drug injection was high for the total sample. The majority $(83.3 \%)$ of women reported having injected any drug in their lifetime and two-thirds (66.7\%) having injected in the 3 months prior to incarceration. Women specifically reported injecting drugs an average of 50.6 days $(S D=42.1)$ in the 3 months prior to incarceration. Compared to other drugs, more participants indicated that they had injected methamphetamine in their lifetime (78.3\%) and in the 3 months prior to incarceration $(66.7 \%)$. More than half of participants reported injecting prescription pain relievers $(63.3 \%)$, cocaine $(58.3 \%)$, and heroin $(53.3 \%)$ in their lifetime.

Regarding risky sexual behavior, women who used social media to find sexual partners were more likely to have exchanged sex for money, drugs, or other goods and services in their lifetime $\left(x^{2}(1, \mathrm{~N}=60)=11.10, p<0.001\right)$ and in the 3 months prior to incarceration $\left(x^{2}(1, \mathrm{~N}=60)=24.83\right.$, $p<0.001)$. They also reported a significantly greater number of sexual partners in the 3 months prior to incarceration $(t(20.1)=-2.08, p=0.050)$ and were more likely to report having a male casual partners in the 3 months prior to incarceration $\left(x^{2}(1, \mathrm{~N}=60)=12.50, p<0.001\right)$ (Table 3$)$.

To further examine the use of social media to connect with sexual partners as a correlate of HIV/HCV risk behavior, we calculated prevalence ratios and $95 \%$ confidence intervals. These analyses focused primarily on risky sexual activity, including exchanging sex and having a casual sex partner, since risky drug use profiles were largely similar across groups. The unadjusted prevalence of exchanging sex for money, drugs, or other goods and services in the 3 months prior to incarceration among those who used social media to find sexual partners was 5.3 times the prevalence among those who did not connect with a sexual partner over social media $(p<0.001 ; 95 \%$ CI $[2.44,11.30])$, while the unadjusted prevalence of reporting a male casual sex partner in the 3 months before incarcerations among those who used social media to find sexual partners was 2.1 times the 
Table 2 Drug use risk by partner connection using social media

\begin{tabular}{|c|c|c|c|c|}
\hline & $\begin{array}{l}\text { Used social media to meet } \\
\text { sexual partner } \\
(\mathrm{n}=21)\end{array}$ & $\begin{array}{l}\text { Did not use social media to meet } \\
\text { sexual partner } \\
(\mathrm{n}=39)\end{array}$ & Test statistic ${ }^{\mathrm{b}}$ & $\mathrm{p}$ value \\
\hline & Mean (SD) & Mean (SD) & & \\
\hline \multicolumn{5}{|l|}{ ASSIST scores } \\
\hline Methamphetamine & $34.6(10.8)$ & $34.4(8.3)$ & $t=-0.06$ & .949 \\
\hline Prescription opioid & $28.3(11.6)$ & $23.9(14.4)$ & $t=-1.21$ & .233 \\
\hline Sedatives/sleeping pills* & $25.7(14.7)$ & $15.8(14.3)$ & $t=-2.54$ & .014 \\
\hline Cannabis & $23.0(11.4)$ & $17.0(12.9)$ & $t=-1.79$ & .079 \\
\hline Street opioid & $22.0(17.2)$ & $15.2(15.1)$ & $t=-1.58$ & .119 \\
\hline Cocaine & $15.5(14.3)$ & $12.9(14.0)$ & $t=-0.67$ & .507 \\
\hline Prescription stimulant* & $14.1(14.7)$ & $6.2(9.3)$ & $t=-2.25$ & .032 \\
\hline \multirow[t]{2}{*}{ Alcohol } & $3.0(1.6)$ & $2.0(1.9)$ & $t=-1.91$ & .061 \\
\hline & Percent (n) & Percent (n) & Test statistic ${ }^{b}$ & $\mathrm{p}$ value \\
\hline \multicolumn{5}{|l|}{ Used in 3 months prior to incarceration } \\
\hline Multiple drugs in 1 day & $95.2(20)$ & $87.2(34)$ & $x^{2}=0.99$ & .321 \\
\hline Methamphetamine & $90.5(19)$ & $89.7(35)$ & $x^{2}=0.01$ & .928 \\
\hline Prescription opioids & $95.2(20)$ & $84.6(33)$ & $x^{2}=1.50$ & .222 \\
\hline Marijuana* & $90.5(19)$ & $61.5(24)$ & $x^{2}=5.63$ & .018 \\
\hline Alcohol** & $81.0(17)$ & $46.2(18)$ & $x^{2}=6.80$ & .009 \\
\hline Anti-anxiety meds & $66.7(14)$ & $43.6(17)$ & $x^{2}=2.91$ & .088 \\
\hline Heroin & $52.4(11)$ & $46.2(18)$ & $x^{2}=0.21$ & .645 \\
\hline Powder cocaine ${ }^{* *}$ & $52.4(11)$ & $15.4(6)$ & $x^{2}=9.20$ & .002 \\
\hline Crack & $33.3(7)$ & $12.8(5)$ & $x^{2}=3.59$ & .058 \\
\hline Downers, sleeping pills, sedatives & $23.8(5)$ & $10.3(4)$ & $x^{2}=1.97$ & .161 \\
\hline Amphetamines* & $19.0(4)$ & $2.6(1)$ & $x^{2}=4.86$ & .028 \\
\hline \multicolumn{5}{|l|}{ Injection drug use } \\
\hline Injected any drug in lifetime & $85.7(18)$ & $82.1(32)$ & $x^{2}=0.13$ & .717 \\
\hline \multicolumn{5}{|c|}{ Injection drug use in the 3 months prior to incarceration... } \\
\hline Any drug & $76.2(16)$ & $61.5(24)$ & $x^{2}=1.32$ & .251 \\
\hline Methamphetamine & $76.2(16)$ & $61.5(24)$ & $x^{2}=1.32$ & .251 \\
\hline Heroin & $42.9(9)$ & $30.8(12)$ & $x^{2}=0.88$ & .349 \\
\hline Prescription pain Relievers & $38.1(8)$ & $17.9(7)$ & $x^{2}=2.96$ & .086 \\
\hline Cocaine & $33.3(7)$ & $12.8(5)$ & $x^{2}=3.59$ & .058 \\
\hline Speedball* & $23.8(5)$ & $5.1(2)$ & $x^{2}=4.62$ & .032 \\
\hline Prescription stimulants & $9.5(2)$ & $5.1(2)$ & $x^{2}=0.42$ & .515 \\
\hline Prescription benzodiazepines & $4.8(1)$ & $2.6(1)$ & $x^{2}=0.21$ & .651 \\
\hline
\end{tabular}

${ }^{a}$ In the 3 months before incarceration

${ }^{\mathrm{b}}$ Test statistic refers to $\mathrm{t}=\mathrm{T}$ test; $\mathrm{x}^{2}=$ Chi-square

$* \mathrm{p} \leq 0.05 ; * \mathrm{p} \leq 0.01$

prevalence among those who did not $(p<0.001 ; 95 \% \mathrm{CI}$ $[1.42,3.04])$.

\section{Discussion}

The overall aims of this paper were to profile HIV/HCV risk behavior among rural Appalachian women, and to explore differences in risk behavior by the use of social media to meet sexual partners. Analyses for the first study objective were primarily descriptive to understand risky drug and sexual practices among this group of women from rural Appalachia. Findings suggest that this randomly selected group of women from rural Appalachian jails self-reported engaging in high rates of drug use, as well as risky drug practices including injection. It is important to note that study inclusion criteria included a score of $4+$ on the NMASSIST for any SI score. Only 3\% of women who were 
Table 3 Sexual risk behavior by social media connection

\begin{tabular}{|c|c|c|c|c|c|c|c|}
\hline & \multicolumn{2}{|c|}{$\begin{array}{l}\text { Used social media to } \\
\text { meet sexual partner } \\
(\mathrm{n}=21)\end{array}$} & \multicolumn{2}{|c|}{$\begin{array}{l}\text { Did not use social } \\
\text { media to meet sexual } \\
\text { partner } \\
(\mathrm{n}=39)\end{array}$} & \multicolumn{2}{|c|}{ Test statistic ${ }^{\mathrm{b}}$} & \multirow{2}{*}{$\begin{array}{l}\mathrm{p} \text { value } \\
p\end{array}$} \\
\hline & Percent (n) & Mean (SD) & Percent (n) & Mean (SD) & $x^{2}$ & $t$ & \\
\hline Age first time had sex & - & $15.0(1.9)$ & - & $15.1(1.9)$ & - & 0.24 & .809 \\
\hline Average number of lifetime sexual partners & - & $71.8(93.5)$ & - & $37.3(67.4)$ & - & -1.65 & .104 \\
\hline $\begin{array}{l}\text { Average number of sex partners in the } 3 \text { months before incar- } \\
\text { ceration* }\end{array}$ & - & $9.5(17.0)$ & - & $1.7(1.3)$ & - & -2.08 & .050 \\
\hline $\begin{array}{l}\text { Had a male casual sex partner in the } 3 \text { months before incarcera- } \\
\text { tion*** }\end{array}$ & $90.5 \%(19)$ & - & $43.6 \%(17)$ & - & 12.50 & - & $<.001$ \\
\hline Reported ever exchanging sex for money or drugs*** & $81.0 \%(17)$ & - & $35.9 \%(14)$ & - & 11.10 & - & $<.001$ \\
\hline $\begin{array}{l}\text { Reported exchanging sex for money or drugs in the } 3 \text { months } \\
\text { before incarceration*** }\end{array}$ & $81.0 \%(17)$ & - & $15.4 \%(6)$ & - & 28.83 & - & $<.001$ \\
\hline Reported having unprotected sex in lifetime & $90.5 \%(19)$ & - & $97.4 \%(38)$ & - & 1.39 & - & .238 \\
\hline $\begin{array}{l}\text { Reported having unprotected sex in the } 3 \text { months before incar- } \\
\text { ceration }\end{array}$ & $85.7 \%(18)$ & - & $87.2 \%(34)$ & - & 0.03 & - & .873 \\
\hline Reporting having unprotected sex with casual partner & $95.2 \%(20)$ & - & $84.6 \%(33)$ & - & 1.50 & - & .222 \\
\hline
\end{tabular}

${ }^{\mathrm{a}}$ In the 3 months before incarceration

${ }^{\mathrm{b}}$ Test statistic refers to $\mathrm{t}=\mathrm{T}$ test; $\mathrm{x}^{2}=$ Chi-square

$* \mathrm{p} \leq 0.05 ; * * * \mathrm{p} \leq 0.001$

randomly selected and screened in the jails did not meet this inclusion criteria. While consistent with other studies with justice-involved women in rural Appalachia [3], these NMASSIST scores are considerably higher than norms for other substance-using women [29]. One notable difference in these findings are, however, that mean SI scores for methamphetamine use were considerably higher among this sample (34.5) compared to an earlier study with rural Appalachian women $(14.9$; [3]). This finding is consistent with other studies [34, 35] signaling a sharp increase in methamphetamine use in recent years, which has been attributed to policy changes around prescription opioid use and misuse. It is also important to note that the majority of women in the current sample reported polysubstance use in their lifetime (98.3\%), as well as in the 3 months before incarceration (90\%).

$\mathrm{HIV} / \mathrm{HCV}$ risk behavior for this study was defined as injection practices and risky sexual activity. The majority of women $(83.3 \%)$ in this sample reported lifetime injection drug use, and about two thirds (66.7\%) reported injecting in the 3 months prior to incarceration. While recruited into the study based on NM-ASSIST scores of 4+, the majority of the sample engaged in high-risk injection drug use, predominantly methamphetamine and prescription opioids. This high prevalence of injection is noteworthy because other findings from this region suggest that injection is closely tied to a high prevalence of $\mathrm{HCV}[14,36,37]$, which is mostly attributed to risky injection practices such as sharing needles and other injection equipment. In addition, women reported high-risk sexual activity including unprotected sexual contacts, high numbers of sexual partners (including sexual partners before incarceration), and more than half reporting exchanging sex for drugs or money in their lifetimes. These findings are consistent with other studies on justice-involved women in general [38], as well as justice-involved women in rural Appalachia [17].

Regular use of social media was a study entry criteria. It is noteworthy that in this randomly selected sample of women from jails, only 10 of the 122 women who screened ineligible $(\sim 5 \%)$ reported that they were not a regular Facebook user. Participants reported using social media for more than $8 \mathrm{~h}$ a week (most reporting use every day) for the purposes of messaging and emailing, daily news, and meeting new people. While these purposes were somewhat expected, the use of social media to identify and connect with potential sex partners was somewhat surprising. The second aim of the study explored possible differences in $\mathrm{HIV} / \mathrm{HCV}$ risk behaviors based on the use of social media to meet sex partners. Most of the literature on the use of social media to connect with sex partners has been done with men and mostly in large urban areas [23-25]. Findings from these studies suggest that connecting with sexual partners via social media is also associated with other high-risk sex among substance users [25, 39]. Findings from this exploratory study with rural Appalachian women who use drugs are consistent with this developing literature in that seeking sex partners on social media was associated with higher risk sexual practices, but not with higher risk drug use practices. Specifically, women who self-reported finding sex partners 
on social media also reported more sex partners, more casual sex partners, and being more likely to exchange sex for drugs or money. Prior research has described varying levels of risk exposure associated with street- and venue-based sex work and specific modes of sex work among women [40, 41], yet the risk environment of social-media based solicitation for transactional sex has been understudied. It is possible that the use of online platforms may transform transactional sex, afford opportunities for more potential sex partners, and increase overall risk exposure, particularly in rural areas that are traditionally characterized by insular social networks. This is a critical area for future research.

Prior research on underserved women in rural Appalachia has largely focused on the need for HIV/HCV prevention services stemming from high rates of injection drug use and risky injection practices [14, 37, 42], with considerably less attention devoted to high risk sexual behaviors. Findings from the current study suggest women who engage in complex risky sexual practices and transactional sex demonstrate elevated patterns of risk. This may be associated with "motivations" for engaging in risky sex, which often includes obtaining money, drugs, or needed services. Appalachian gender norms may also contribute in that women are typically expected to stay home and care for the family, which may make them more reliant on male partners for drugs [14]. Thus, rural Appalachian women who engage in high risk sexual practices may represent a unique target population in need of multipronged prevention and risk reduction interventions. In rural communities where prevention resources and treatment services may be limited, these findings have important implications for future research with Appalachian women.

This study has some notable limitations. Women were randomly selected and recruited for the study as a small pilot to examine social media use and HIV/HCV risk behavior from two purposefully selected rural Appalachian area jails. It should be recognized that this limits generalizability to other substance-using women involved in the criminal justice system outside of rural Appalachia. The small sample size also limited more complex logistic regression analysis with multiple covariates. Findings related to identification of sex partners using social media were not anticipated, so measurement was limited regarding risk behavior associated with actually connecting with those sex partners and the temporal relationship of risky sexual practices and drug use following community reentry. It should also be noted that while self-reported data collected related to high-risk drug use and sexual practices is common in this area of research [3], it is possible that discussing this type of sensitive information may have led to social desirability response bias. In addition, considering that all study participants were incarcerated at the time of the baseline, there may always be concerns related to confidentiality. Participants were assured of IRB protections, as well as the protections of the Certificate of Confidentiality. Also, study participants were recruited based on self-reported HIV negative status, which may exclude women engaging in higher risk behaviors which should be an important target for future research. Finally, while preliminary analysis did not detect any notable differences in data collected in person versus videoconferencing, it is always possible that the onset of COVID-19 and resulting visitation restrictions at the jail may have impacted participants study involvement.

\section{Conclusions}

Despite these limitations, these findings have important implications for HIV/HCV prevention intervention development and testing, particularly within social media platforms. In particular, not only is Facebook use common among rural women, but Facebook has also been a useful tool for research. A retrospective analysis of a study with criminal justice involved women showed that almost half of participants opted into a Facebook group used to share study information [43]. Social media has also been identified as a valuable tool for maintaining contact with criminal justice-involved women in research studies, including rural women [22, 43, 44]. These study findings suggest that the use of social media for high-risk sexual practices may be a critical marker for other high-risk sexual practices. Considering the widespread use of Facebook, this and other social media platforms may provide valuable opportunities for intervention delivery, particularly in resource-deprived areas where formal prevention and treatment services are limited. As research develops in this area, it is critical to take into consideration both the individual level factors associated with HIV transmission (risky drug use and sexual practices) and the population level factors (limited resources and service opportunities) [45] that lead to the need for culturally tailored and unique interventions to reduce $\mathrm{HIV} / \mathrm{HCV}$ risk in rural Appalachia.

Acknowledgements Research reported in this manuscript was supported by the National Institute on Drug Abuse of the National Institutes of Health under Awards R34DA045563. The content is solely the responsibility of the authors and does not necessarily represent the official views of the National Institutes of Health. We would also like to recognize the cooperation and partnership with the [state] Department of Corrections and the local jails participating in this study.

Author Contributions MS, EP, HS, and SY contributed to the study design. Data analysis were performed by MFD. The first draft of the manuscript was written by MS and all authors commented on previous versions of the manuscript. All authors read and approved the final manuscript. 
Funding Research reported in this manuscript was supported by the National Institute on Drug Abuse ofthe National Institutes of Health under Awards R34DA045563.

Data Availability De-identified data is available upon request to the corresponding author.

Code Availability Not applicable.

\section{Declarations}

Conflict of interest The authors have no conflicts of interest to declare.

Ethical Approval All study procedures were approved by the University of Kentucky IRB and were performed in accordance with the ethical standards in the Declaration of Helsinki.

Consent to Participate All study participants provided their informed consent prior to participation.

Consent for Publication Participants were informed in the informed consent that the results of the study may be published in aggregate and individuals would not be identified in any publications.

\section{References}

1. Centers for Disease Control and Prevention. Estimated HIV incidence and prevalence in the United States, 2015-2019. 2021 May (HIV Surveillance Supplemental Report). Report No. 26(No. 1).

2. Qin Y, Price C, Rutledge R, Puglisi L, Madden LM, Meyer JP. Women's decision-making about PrEP for HIV prevention in drug treatment contexts. J Int Assoc Provid AIDS Care. 2020;19:232595821990009.

3. Staton M, Ciciurkaite G, Oser C, Tillson M, Leukefeld C, Webster JM, et al. Drug use and incarceration among rural Appalachian women: findings from a jail sample. Subst Use Misuse. 2018;53(6):931-41.

4. Young AM, Larian N, Havens JR. Gender differences in circumstances surrounding first injection experience of rural injection drug users in the United States. Drug Alcohol Depend. 2014;134:401-5.

5. Brookmeyer KA, Haderxhanaj LT, Hogben M, Leichliter J. Sexual risk behaviors and STDs among persons who inject drugs: a national study. Prev Med. 2019;126:105779.

6. Tompkins CNE, Sheard L, Wright NMJ, Jones L, Howes N. Exchange, deceit, risk and harm: the consequences for women of receiving injections from other drug users. Drugs Educ Prev Pol. 2006;13(3):281-97.

7. Pitasi MA, Delaney KP, Brooks JT, DiNenno EA, Johnson SD, Prejean J. HIV testing in 50 local jurisdictions accounting for the majority of new HIV diagnoses and seven states with disproportionate occurrence of HIV in rural areas, 2016-2017. MMWR Morb Mortal Wkly Rep. 2019;68(25):561-7.

8. Bronson J. Drug use, dependence, and abuse among state prisoners and jail inmates, 2007-2009. Bureau of Justice Statistics, U.S. Department of Justice; 2017.

9. Loeliger KB, Biggs ML, Young R, Seal DW, Beckwith CG, Kuo I, et al. Gender differences in HIV risk behaviors among persons involved in the U.S. Criminal Justice System and living with HIV or at risk for HIV: a "seek, test, treat, and retain" harmonization consortium. AIDS Behav. 2017;21(10):2945-57.
10. Jones AA, Gerke T, Striley CW, Whitehead N, Osborne V, Cottler LB. One step at a time: a latent transitional analysis on changes in substance use, exposure to violence, and HIV/AIDS risk behaviors among female offenders. Am J Crim Just. 2018;43(3):471-85.

11. Noska AJ, Roberts MB, Sufrin C, Stein LAR, Beckwith CG, Rich JD, et al. History of sex exchange in women with a history of incarceration. J Health Care Poor Underserved. 2016;27(2A):149-62.

12. Slavin MN, Hochstatter K, Kraus SW, Earleywine M, El-Bassel $\mathrm{N}$. Associations between cannabis use and sexual risk behavior among women under community supervision: a brief report. Int J Sex Health. 2021;33(2):123-30.

13. Hearn LE, Whitehead NE, Khan MR, Latimer WW. Time since release from incarceration and HIV risk behaviors among women: the potential protective role of committed partners during re-entry. AIDS Behav. 2015;19(6):1070-7.

14. Staton-Tindall M, Harp KLH, Minieri A, Oser C, Webster JM, Havens J, et al. An exploratory study of mental health and HIV risk behavior among drug-using rural women in jail. Psychiatr Rehabil J. 2015;38(1):45-54.

15. Ramaswamy M, Kelly PJ. Sexual health risk and the movement of women between disadvantaged communities and local jails. Behav Med. 2015;41(3):115-22.

16. Oser CB, Pullen E, Stevens-Watkins D, Perry BL, Havens JR, Staton-Tindall M, et al. African American women and sexually transmitted infections: the contextual influence of unbalanced sex ratios and individual risk behaviors. J Drug Issues. 2017;47(4):543-61.

17. Staton M, Strickland JC, Tillson M, Leukefeld C, Webster JM, Oser CB. Partner relationships and injection sharing practices among rural Appalachian women. Womens Health Issues. 2017;27(6):652-9.

18. Auxier B, Anderson M. Social Media Use in 2021 [Internet]. 2021. https://www.pewresearch.org/internet/2021/04/07/socialmedia-use-in-2021/. Cited 2021 Sep 26

19. Gilbert E, Karahalios K, Sandvig C. The network in the garden: designing social media for rural life. Am Behav Sci. 2010;53(9):1367-88.

20. Young SD, Lee S-J, Perez H, Gill N, Gelberg L, Heinzerling $\mathrm{K}$. Social media as an emerging tool for reducing prescription opioid misuse risk factors. Heliyon. 2020;6(3):e03471.

21. Young SD, Shoptaw S. Stimulant use among African American and Latino MSM social networking users. J Addict Dis. 2013;32(1):39-45.

22. Dickson MF, Staton-Tindall M, Smith KE, Leukefeld C, Webster JM, Oser CB. A Facebook follow-up strategy for rural drug-using women: Facebook follow-up. J Rural Health. 2017;33(3):250-6.

23. Broaddus MR, DiFranceisco WJ, Kelly JA, St. Lawrence JS, Amirkhanian YA, Dickson-Gomez JD. Social media use and highrisk sexual behavior among black men who have sex with men: a three-city study. AIDS Behav. 2015;19(S2):90-7.

24. Meunier É, Cai X, Bamonte A, Callander D, Schrimshaw EW. Exchange sex and condom use among gay, bisexual, and other men who have sex with men who use social and sexual networking technologies. Ann LGBTQ Public Popul Health. 2021;2(2):166-80.

25. Young SD, Szekeres G, Coates T. The relationship between online social networking and sexual risk behaviors among men who have sex with men (MSM). Muldoon MR, editor. PLoS ONE. 2013;8(5):e62271.

26. Tsai JY, Sussman S, Pickering TA, Rohrbach LA. Is online partner-seeking associated with increased risk of condomless sex and sexually transmitted infections among individuals who engage in heterosexual sex? A systematic narrative review. Arch Sex Behav. 2019;48(2):533-55. 
27. Studts CR, Tillson M, Pike E, Staton M. Adaptation of the NIDA standard for delivery via Facebook with justiceinvolved women in rural Appalachia. Implement Res Pract. 2021;2:263348952110141.

28. National Institute on Drug Abuse (NIDA). NIDA ModifiedASSIST [Internet]. 2009. http://www.drugabuse.gov/nidamed/ screening/. Cited 26 Sep 2021

29. Oga EA, Mark K, Peters EN, Coleman-Cowger VH. Validation of the NIDA-modified ASSIST as a screening tool for prenatal drug use in an urban setting in the United States. J Addict Med. 2020;14(5):423-30.

30. Dennis ML, White M, Titus JC, Unsicker J. Global appraisal of individual needs: administration guide for the GAIN and related measures [Internet]. Chestnut Health Systems; 2008. http://www. chestnut.org/li/gain.

31. Wechsberg WM. Revised risk behavior assessment, part I and part II. Research Triangle Park: Research Triangle Institute; 1998.

32. Espelt A, Marí-Dell'Olmo M, Penelo E, Bosque-Prous M. Estimación de la Razón de Prevalencia con distintos modelos de Regresión: Ejemplo de un estudio internacional en investigación de las adicciones. Adicciones. 2016;29(2):105.

33. Holmberg MJ, Andersen LW. Estimating risk ratios and risk differences: alternatives to odds ratios. JAMA. 2020;324(11):1098.

34. Ellis MS, Kasper ZA, Cicero TJ. Twin epidemics: the surging rise of methamphetamine use in chronic opioid users. Drug Alcohol Depend. 2018;193:14-20.

35. Wedenoja $\mathrm{L}$. The second wave of the methamphetamine epidemic [Internet]. 2020. https://rockinst.org/blog/the-second-wave-of-themethamphetamine-epidemic/. Cited 26 Sep 2021.

36. Cloud DH, Ibragimov U, Prood N, Young AM, Cooper HLF. Rural risk environments for hepatitis $\mathrm{c}$ among young adults in Appalachian Kentucky. Int J Drug Policy. 2019;72:47-54.

37. Havens JR, Lofwall MR, Frost SDW, Oser CB, Leukefeld CG, Crosby RA. Individual and network factors associated with prevalent hepatitis c infection among rural Appalachian injection drug users. Am J Public Health. 2013;103(1):e44-52.

38. Knittel AK, Lorvick J. Self-reported sexually-transmitted infections and criminal justice involvement among women who use drugs. Addict Behav Rep. 2019;10:100219.

39. Young SD, Zheng K, Chu LF, Humphreys K. Internet searches for opioids predict future emergency department heroin admissions. Drug Alcohol Depend. 2018;190:166-9.

40. Prior J, Hubbard P, Birch P. Sex worker victimization, modes of working, and location in New South Wales, Australia: a geography of victimization. J Sex Res. 2013;50(6):574-86.

41. Surratt HL, Kurtz SP, Weaver JC, Inciardi JA. The connections of mental health problems, violent life experiences, and the social milieu of the "stroll" with the HIV risk behaviors of female street sex workers. J Psychol Human Sex. 2005;17(1-2):23-44.

42. Fraser H, Vellozzi C, Hoerger TJ, Evans JL, Kral AH, Havens J, et al. Scaling Up Hepatitis C prevention and treatment interventions for achieving elimination in the United States: a rural and urban comparison. Am J Epidemiol. 2019;188(8):1539-51.

43. Lipnicky A, Kelly PJ, Ramaswamy M. Facebook as a follow-up tool for women with criminal justice histories. Int J Public Health. 2020;16(2):117-22.

44. Wickliffe J, Kelly PJ, Allison M, Emerson A, Ramaswamy M. Retention strategies in working with justice-involved women. J Correct Health Care. 2019;25(3):231-7.

45. Rose G. Sick individuals and sick populations. Int J Epidemiol. 2001;30(3):427-32.

Publisher's Note Springer Nature remains neutral with regard to jurisdictional claims in published maps and institutional affiliations. 